\title{
Does Academic Dishonesty Relate to Unethical Behavior in Professional Practice? An Exploratory Study*
}

\author{
Trevor S. Harding, ${ }^{*}$ Donald D. Carpenter, ${ }^{\dagger}$ Cynthia J. Finellii ${ }^{\ddagger}$ \\ and Honor J. Passow ${ }^{\ddagger}$ \\ * Kettering University, Flint, Michigan; ${ }^{+}$Lawrence Technological University, Southfield, \\ Michigan; ${ }^{\ddagger}$ University of Michigan, Ann Arbor, Michigan
}

Keywords: academic dishonesty, cheating, professional ethics, engineering education

\begin{abstract}
Previous research indicates that students in engineering self-report cheating in college at higher rates than those in most other disciplines. Prior work also suggests that participation in one deviant behavior is a reasonable predictor of future deviant behavior. This combination of factors leads to a situation where engineering students who frequently participate in academic dishonesty are more likely to make unethical decisions in professional practice. To investigate this scenario, we propose the hypotheses that (1) there are similarities in the decision-making processes used by engineering students when considering whether or not to participate in academic and professional dishonesty, and (2) prior academic dishonesty by engineering students is an indicator of future decisions to act dishonestly. Our sample consisted of undergraduate engineering students from two technically-oriented private universities. As a group, the sample reported working full-time an average of six months per year as professionals in addition to attending classes during the remaining six months. This combination of both academic and professional experience provides a sample of students who are experienced in both settings. Responses to open-ended questions on an exploratory survey indicate that students identify common themes in describing both temptations to cheat or to violate workplace policies and factors which caused them to
\end{abstract}

\footnotetext{
* An earlier version of this paper was presented at the "Ethics and Social Responsibility in Engineering and Technology" meeting, New Orleans, 2003.

Address for correspondence: Donald D. Carpenter, Civil Engineering, Lawrence Technological University, Southfield, MI 48075, USA; email: carpenter@1tu.edu.

Trevor S. Harding is in the Industrial and Manufacturing Engineering Dept. at Kettering University, Flint, MI; Cynthia J. Finelli is at the Center for Research on Learning and Teaching, University of Michigan, Ann Arbor, MI; Honor J. Passow is at the School of Education, University of Michigan, Ann Arbor, MI.

1353-3452 @ 2004 Opragen Publications, POB 54, Guildford GU1 2YF, UK. http://www.opragen.co.uk
} 
hesitate in acting unethically, thus supporting our first hypothesis and laying the foundation for future surveys having forced-choice responses. As indicated by the responses to forced-choice questions for the engineering students surveyed, there is a relationship between self-reported rates of cheating in high school and decisions to cheat in college and to violate workplace policies; supporting our second hypothesis. Thus, this exploratory study demonstrates connections between decision-making about both academic and professional dishonesty. If better understood, these connections could lead to practical approaches for encouraging ethical behavior in the academic setting, which might then influence future ethical decision-making in workplace settings.

\section{Introduction}

Academic dishonesty, known commonly as cheating, has been a consistent problem for many years at all educational levels; however, several studies indicate that the level of cheating among students in college has increased steadily over the past forty years. Of direct importance to engineering educators is the fact that students in engineering are among those most likely to engage in academic dishonesty. In the largest study to date, conducted in 1964, Bowers ${ }^{3}$ reported that $58 \%$ of engineering students self-reported cheating in college. By comparison, in 1996 McCabe $^{11}$ reported that $82 \%$ of engineering students self-reported cheating. In both cases, students in engineering reported the second-highest rates of cheating by academic discipline, behind only business students.

The consequences of these high rates of academic dishonesty among engineering students are clear. For students who cheat there are personal consequences, such as missing the opportunity to develop a deep understanding of the content material. Over time, such students may develop a sense that everyone else cheats, that it is easy to do, and that it is a normal part of life. In essence, such students become desensitized to the academic cultural norm of integrity in learning. Furthermore, not only the academy but also society must contend with the consequences of student cheating. Faculty evaluate students who cheat on the basis that the falsely-completed work is a valid assessment of the students' knowledge and capabilities. This in turn provides prospective employers with an inaccurate impression of the students' abilities. Perhaps more serious, however, is the idea that the behaviors that result in low academic integrity could well extend into professional practice - resulting in significant consequences for the individual, the employer, its customers, and society in general.

One might consider cheating at the college level to be a deviant behavior, since it varies from the cultural norm of academic integrity. Likewise, violating workplace policies, whether internally or externally mandated, might also be considered a deviant behavior. A logical question follows from these assumptions: is participation in one deviant behavior (i.e., cheating) a predictor of participation in another deviant behavior in future settings (i.e., violating workplace policies)? 
In a study based on their "Theory of Planned Behavior," Beck and Ajzen ${ }^{1}$ asserted that prior and future behaviors are correlated only to the extent that the underlying determinants-such as attitudes, subjective norms, perceptions of behavioral control, and intentions - have not changed over time. Therefore, for example, if a correlation exists between high school cheating and college cheating, one must presume that influences other than situational factors (which clearly change) affect the student's decision to cheat. Several studies have found correlations between academic dishonesty and other deviant behavior, including risky driving, ${ }^{4}$ theft from employers, ${ }^{5}$ shoplifting, ${ }^{3}$ alcohol abuse, ${ }^{6}$ and cheating on income taxes. ${ }^{7}$

These findings suggest that there may be certain common factors that influence an individual's decision to engage in deviant behaviors such as cheating and violating workplace policies. If this inference is valid, then high rates of self-reported academic dishonesty, such as those that occur among engineering students, may be correlated with high rates of engaging in unethical behavior in professional practice.

Our research is driven by two hypotheses: 1) that there are similarities in the decision-making processes students use when considering whether or not to cheat in college and whether or not to violate workplace policies, and 2) that prior academic dishonesty is an indicator of future dishonest behavior. To investigate these hypotheses, we have developed an exploratory survey that asks respondents about decisions during opportunities to engage in deviant behavior in each of two contexts: college and workplace settings. For each context, respondents were asked to consider a specific instance in which they had been tempted to engage in deviant behavior, to identify pressures they felt to engage in this behavior, to describe factors that caused them to hesitate to engage in this behaviour, and to describe the decision they ultimately made. This paper will present both qualitative and quantitative data from the survey and will do so in an aggregate way. Analysis of the relationship between the context and the decision for individual responses will be discussed in future publications.

\section{Methodology}

\section{Sample Description}

A total of 130 students enrolled at two technically-oriented private universities responded to the survey. To maximize the response rate, students were asked to complete the survey in their classes (for this study the response rate was $85.9 \%$ ). The sample consisted of second year (7\%), third year $(42 \%)$, fourth year $(33 \%)$ and fifth year (16\%) engineering undergraduate students. First year students were not included in the sample because of their lack of experience in either the academic or professional setting. Participants reported having full-time employment for an average of $6.78 \pm 2.97$ months during the last academic year and working an average of $38.7 \pm 10.8$ hours per week while employed full-time. One limitation of this study is the potential for a difference in the moral development and maturity of the individuals included in the sample. These attributes may not be as fully developed in college students, despite having considerable work experience, as they are in practicing engineers who have 
already graduated from college. However, we feel that this limitation is outweighed by the advantage of using a single sample of students for both the academic dishonesty and unethical behavior in professional practice portions of the study.

\section{Survey}

Participants completed a thirteen-item questionnaire consisting of three sections. The first section contained questions related to the respondents' backgrounds, including the extent to which they worked in the past year and the frequency with which they cheated in high school. The second section dealt with issues regarding student decisions about cheating in college, and the third section dealt with issues regarding student decisions about violating workplace policies.

As with any study on deviant behavior that uses a self-report questionnaire approach, underreporting due to social desirability is a concern. ${ }^{8}$ Despite this possible source of error, there is evidence that in many situations self-reports of dishonest behaviors can be accurate. ${ }^{9}$ For this study, care was taken to develop protocols that assured respondent anonymity: the questionnaire was distributed during a regularlyscheduled class period by one author of this paper, the proctor briefly discussed the nature of the research and the participants' rights and then left the room while participants completed the questionnaire, respondents were asked to place completed surveys into a large plain envelope which was sealed and returned to a department administrative assistant, and the surveys were delivered to the proctor for data entry and subsequent analysis. This protocol and the survey itself were approved by the University of Michigan Institutional Review Board for the Behavioral Sciences.

During the survey, respondents were asked to consider one specific instance in which they were tempted to cheat in college and one specific instance in which they were tempted to violate the workplace policies of the company where they were employed full-time. All of the students related such an incident in college, but only $70 \%$ of the respondents identified a workplace scenario- $40 \%$ described a situation related to an engineering occupation, $10 \%$ described a situation related to retail, restaurant, or service work, $10 \%$ described a trades or construction-related situation, and $10 \%$ indicated some other work environment. Although $30 \%$ of the students did not describe an event in which they were tempted to violate workplace policies, respondents who did not work for pay during the last year were asked to skip this section of the survey. Therefore, one can neither conclude that $30 \%$ of the respondents were not tempted or that $30 \%$ of the respondents were not employed full-time.

\section{Academic Dishonesty}

Table $1^{\mathrm{a}}$ presents the self-reported frequency of cheating during an average term in high school. The majority of respondents $(63.8 \%)$ indicated cheating at least a few times per term, and $79.2 \%$ of the respondents indicated that they cheated at least once per term. Although similar data was not collected on this survey regarding frequency of

a. Tables 1-12 can be viewed on pp. xxx-xxx. Publisher to add pp. nos. 
cheating in college, a previous study by these authors estimates that $96 \%$ of engineering students within a similar sample had cheated at least once while in college. ${ }^{10}$ Data is not available for a comparison by term in this case.

In the second section of the survey, respondents were asked to indicate how frequently they were tempted to cheat on various forms of assessment during their most recent term in college. Frequency data is presented in

Table 2. Average scores for these assessments, based on a 5-point Likert scale, are shown in the far right column. Respondents indicated that they were most frequently tempted to cheat on homework, followed by lab reports, and then tests or quizzes. Participants reported that they were least likely to be tempted to cheat on team projects, term papers, and final exams. Average scores were significantly different as determined by a Friedman non-parametric test $\left(\chi^{2}=171.3, \mathrm{df}=6, \mathrm{p}<0.001\right)$.

Through free-response questions, respondents were then asked to consider a specific instance in which they were tempted to cheat and asked to describe the pressures that led them to consider cheating in that situation. As part of the qualitative data analysis, the resulting responses were copied onto index cards by three independent evaluators who each categorized the responses into themes. The independent evaluators then met to discuss their themes and came to a consensus about common themes (Table 3). This data suggests that the respondents had a wide range of reasons for justifying cheating. The single most common temptation to cheat was, by a considerable margin, not enough time to complete assignments, reports, etc. $(23.1 \%$ of valid responses). This may suggest that many students perceive cheating in school as a time-saving mechanism, rather than as a means of gaining an advantage over others. One could argue that this is related to the second most frequent response of being unprepared for the assessment (14.1\% of valid responses). Students who lack time to complete assessments will often be unprepared for those assessments. However, there are other potential explanations for being unprepared, so these two pressures remain separate. Students also indicated that lack of motivation (10.9\%), grade pressure $(10.3 \%)$, a professor who deserved it $(9.0 \%)$, and material too hard $(8.3 \%)$ were additional pressures to consider cheating. These responses could be described as situational, insofar as the respondent felt justified in cheating because of the particularly difficult circumstances of the situation.

Respondents were also asked to consider factors (i.e., thoughts, feelings, social pressures, or school policies) that caused them to hesitate to cheat in the situation they identified. These free responses were categorized into emerging themes for analysis by the evaluators and are listed in Table 4. The most frequent response was associated with shame, conscience, guilt, or loss of personal respect (17.7\% of valid responses). This could be described as a hesitation to cheat based on potential negative consequences. Other factors also are based on potential negative consequences - fear or high probability of getting caught and fear of sanctions-and $37.9 \%$ of the responses are classified in this larger grouping. On the other hand, $26.6 \%$ of respondents indicated hesitations to cheat based on positive consequences-desire to learn and desire to do own work. It should be noted that the hesitation cheating is wrong includes eleven responses with exactly this wording. The evaluators could not 
agree on why the respondent felt cheating was wrong, and as such, these responses were left in their own group.

Data from the survey indicated that $36.2 \%$ of respondents decided to cheat in the situation they identified, while $50.0 \%$ chose not to ( $13.8 \%$ provided no response). Table 5 presents a comparison of respondent's decision about cheating as a function of form of assessment for the 112 students who responded. Since respondents were asked to consider only one scenario, it is impossible to determine how an individual student might respond in a different scenario; however, comparisons can be made about the decision to cheat in the aggregate. As indicated in

Table 2, respondents were most frequently tempted to cheat on homework and tests or quizzes. However, $45.2 \%$ of respondents who were tempted to cheat on homework ultimately did cheat, while only $33.3 \%$ of those tempted to cheat on tests or quizzes did cheat. As a further comparison, only $14.3 \%$ of respondents who were tempted to cheat on a final exam actually cheated. An interesting observation is that more students cheated on lab reports (66.7\%) and computer programs (58.3\%) than did not. These results are not surprising, as previous data has shown that respondents' perceptions of cheating are influenced significantly by the nature of the assessment. ${ }^{10,11}$

\section{Unethical Behavior in Professional Practice}

In the third section of the survey, respondents were asked to estimate how frequently they were tempted to consider violating workplace policies in several different scenarios. This data, presented in Table 6, indicates that respondents were most frequently tempted to use company supplies improperly (average score $=1.98$ ). In this study, as many as $48.8 \%$ of respondents indicated that they were tempted to use company supplies or equipment improperly at least once while working at their company, a finding that is in agreement with research that indicates that employee theft is the primary source of crime-related losses to businesses. ${ }^{12}$ The scenario in which students reported the next highest level of temptation was to falsify records such as time sheets, expense reports, and quality assurance documents-31.5\% of the respondents reported a temptation to engage in this activity at least once during the past year. Other tempting scenarios include ignoring quality problems (22.4\%), lying about work quality (16.9\%), ignoring safety problems (15.2\%), accepting improper gifts $(11.2 \%)$, and taking credit for another's work (9.6\%). Average scores were significantly different as determined by a Friedman non-parametric test $\left(\chi^{2}=111.0\right.$, $\mathrm{df}=6, \mathrm{p}<0.001)$.

As with cheating, respondents were asked to consider a specific instance in which they were tempted to violate workplace policies and to describe the pressures that led them to consider violating the workplace policies. Table 7 presents the results of this analysis. Overwhelmingly, the largest theme was that of the respondent indicating they wanted or needed something ( $21.8 \%$ of respondents). This is not surprising, given that improper use of company supplies was the most common scenario in which respondents were tempted to violate workplace policies. The second most common response was that the activity was inconsequential or seemed harmless $(10.3 \%)$. This is 
followed by a sense that the company deserved it $(8.0 \%)$ and that there was a lack of time, money, or equipment to do the job correctly $(8.0 \%)$.

Finally, respondents were asked to indicate factors that caused them to hesitate in their decision to violate the workplace policies of their employer. Themes from this analysis are presented in Table 8 . Somewhat surprisingly, equal numbers of respondents $(13.8 \%)$ said they felt no hesitation to violate policies, they hesitated because of their own positive personal standards, and they hesitated because they might get fired or get in trouble. Fear of getting caught and it is wrong were also common factors the respondents listed as hesitations.

Overall, of the respondents who indicated that they had been tempted to violate company policies in some way, $30.0 \%$ did violate the policies, $15.4 \%$ did not, and $10.8 \%$ followed some other course of action (Table 9). A total of $43.8 \%$ of respondents chose not to provide a response to this question. Such a large number of missing responses could indicate the possibility of substantial bias in the responses; however, a review of other, unreported questions in the survey shows that $30.0-36.2 \%$ of responses are also missing in these questions. This suggests that a smaller number of respondents than initially apparent may have chosen not to answer the question regarding their ultimate decision to violate workplace policies because of social desirability bias.

Table 9 provides a comparison of the respondent's decision about violating workplace policies as a function of the type of scenario the respondent was considering. Though sample size is quite small in some instances, it appears that more respondents used company supplies when tempted than did not, and more falsified records when tempted than did not (A review of free-response comments from respondents indicates that these records were typically time cards).

\section{Comparisons across Context}

Because one focus of this study was to investigate the connection between prior behavior and future decision making, it is informative to examine the relationship between self-reported levels of cheating in high school and the decision about cheating and violating workplace policies (Table 10). Though statistical significance cannot be established due to small sample sizes, there is a clear trend in the data. Table 10 shows that respondents who indicated more frequent cheating in high school were more likely to indicate a decision to cheat in the scenario they were considering. For example, only $31.6 \%$ of respondents who reported never cheating in high school indicated that they did decide to cheat in the college scenario, while $68.4 \%$ decided not to cheat. On the other hand, of the respondents who reported frequently cheating in high school, $61.5 \%$ cheated in the specific situation in college, while only $38.5 \%$ did not. Similar observations can be made when comparing the self-reported frequency of high school cheating to the decision about violating workplace policies. Only $37.5 \%$ of respondents who reported never cheating during an average term in high school decided to violate their workplace policies, whereas $63.6 \%$ of respondents who frequently cheated in high school also violated the policies. The data in Table 10 seem to confirm that past 
behavior (cheating in high school) can be a strong indicator of future behavior (cheating in college and violating workplace policies).

Examination of the qualitative responses shows a remarkable similarity in the nature of the responses, though not necessarily in their relative frequency. For example, in comparing the student responses about pressures to cheat in a specific scenario (Table 3) and to violate workplace policies (Table 7), one sees that most responses are common across the two questions. The extent of commonality in the responses suggests that there are substantial similarities in the decision-making processes that students use with regard to academic dishonesty and unethical behavior in professional practice. In Table 11, the common responses are compiled together and each pair has been given a new variable name to clarify the responses. It is of note that some responses could not be grouped across the two questions. For example, in terms of the pressures to cheat in college, respondents indicated that being unprepared, lacking motivation, and perceiving that cheating works were all temptations to cheat. However, similar responses could not be identified among those for violating workplace policies. Similarly, in the case of violating workplace policies there were several responses that did not match with those for cheating, including: wanted or needed it, inconsequential or seemed harmless, wanted to avoid conflict, someone told me to do it and no one would care. Despite the lack of matching pairs for these responses, it is quite likely that these are important variables in the decision-making process, and that they did not appear in this limited data set.

Similarly, Table 12 describes commonalities in the responses about hesitations to cheat and to violate workplace policies. Here again, the substantial number of common responses between academic and professional settings suggests that there are in fact common hesitations that affect an individual's decision about whether or not to engage in deviant behavior. As before, however, there are some responses that do not agree. For example, in the case of academic dishonesty some respondents indicated that it was physically too hard or time-consuming to cheat. No common pairing could be found among the responses for the workplace setting. Likewise, among the responses for hesitations to violate workplace policies several responses were unpaired, including: negative consequences for customers, work had to get done and it could affect product quality. These responses relate to specific scenarios and do not necessarily occur in academic settings. However, an argument could be made to group these responses under the common variable moral obligation.

\section{Conclusions}

The study described in this paper was intended to explore the relationship between academic dishonesty in high school and college and unethical behavior in professional practice among engineering students. As a consequence of this work, several conclusions have been reached:

- Through qualitative analysis of open-ended responses, substantial commonalities have been identified between the elements of the decision-making process with regard to academic dishonesty and unethical behavior in professional practice, supporting our first hypothesis. Identification of these common elements will allow 
for the eventual creation of a model of the decision-making process as it relates to both the academic and professional setting.

- There appears to be a strong relationship between self-reported involvement in prior academic dishonesty (high school) and self-reported involvement in present dishonest behavior (college and workplace) of engineering students. This finding supports our second hypothesis that past deviant behavior is an indicator of future deviant behavior. It suggests that many students, despite changes in context from high school to college and to the workplace, will make the same ultimate decision when faced with a temptation to engage in deviant behavior.

- The investigative approach was intended as an initial exploration of the underlying decision-making processes in both academic and professional situations where the respondent was tempted to engage in deviant behavior. As expected, the themes that emerged from the free-response questions provide direction for future research that will involve a survey with more forced-choice questions. Such a survey design will enable larger sample sizes and more sophisticated statistical analysis and will allow further understanding of the possible relationship between academic dishonesty and unethical behavior in professional practice.

\section{REFERENCES}

1. Bowers, W.J. (1964). Student Dishonesty and its Control in College, Bureau of Applied Social Research, Columbia University.

2. McCabe, D.L. (1997). "Classroom Cheating Among Natural Science and Engineering Majors." Science and Engineering Ethics 3: 433-445.

3. Beck, L. and I. Ajzen (1991). "Predicting Dishonest Actions Using the Theory of Planned Behavior." Journal of Research in Personality 25: 285-301.

4. Blankenship, K.L. and B.E. Whitley (2000). "Relation of General Deviance to Academic Dishonesty." Ethics and Behavior 10(1): 1-12.

5. Hilbert, G.A. (1985). "Involvement of Nursing Students in Unethical Classroom and Clinical Behaviors." Journal of Professional Nursing 1: 230-234.

6. Kerkvliet, J. (1994). "Cheating by Economics Students: A Comparison of Survey Results." Journal of Economic Education 25: 121-133.

7. Fass, R.A. (1989). Cheating and Plagiarism. Ethics and Higher Education. W.W. May. New York, Macmillan: 170-184.

8. Edwards, A.L. (1957). Techniques of Attitude Scale Construction. Appleton-Century-Crofts, New York.

9. Himmelfarb, S. and C. Lickteig (1982). "Social Desirability and the Randomized Response Technique." Journal of Personality and Social Psychology 43(4): 710-717.

10. Carpenter, D.D., T.S. Harding, et. al. (2002). P.A.C.E.S. - A Study on Academic Integrity among Engineering Undergraduates (Preliminary Conclusions). Proceedings of the 2002 American Society for Engineering Education Annual Conference. Montreal, Canada.

11. Finelli, C.J., T.S. Harding, et. al. (2003). "Students' Perceptions of both the Certainty and the Deterrent Effect of Potential Consequences to Cheating." Proceedings of the American Society for Engineering Education Annual Conference, Nashville, TN.

12. Nonis, S. and C.O. Swift (2001). "An Examination of the Relationship Between Academic Dishonesty and Workplace Dishonesty: A Multicampus Investigation." Journal of Education for Business: 69-77. 
T. S. Harding, D. D. Carpenter, C. J. Finelli, H. J. Passow

\section{TABLES}

Table 1: Frequency of cheating during an average high school term

\begin{tabular}{|l|l|}
\hline Frequency & \\
\hline Never & $20.0 \%$ \\
Once & $15.4 \%$ \\
A few times & $53.8 \%$ \\
Frequently & $10.0 \%$ \\
\hline
\end{tabular}

Table 2: Frequency with which respondents were tempted to cheat during most recent college term for various forms of assessment

\begin{tabular}{|l|c|c|c|c|c|c|}
\hline Form of assessment & $\begin{array}{c}\text { Never } \\
(\%)\end{array}$ & $\begin{array}{c}\text { Once } \\
(\%)\end{array}$ & $\begin{array}{c}2-5 \\
\text { times } \\
(\%)\end{array}$ & $\begin{array}{c}5-10 \\
\text { times } \\
(\%)\end{array}$ & $\begin{array}{c}10+ \\
\text { times } \\
(\%)\end{array}$ & $\begin{array}{c}\text { Average } \\
\text { score* }^{*}\end{array}$ \\
\hline Homework & 23.1 & 17.7 & 33.8 & 15.4 & 7.7 & $\mathbf{2 . 6 6}$ \\
Lab report & 50.8 & 12.3 & 24.6 & 6.2 & 4.6 & $\mathbf{2 . 0 0}$ \\
Test or quiz & 42.3 & 20.8 & 29.2 & 3.8 & 1.5 & $\mathbf{1 . 9 9}$ \\
Computer program & 60.0 & 11.5 & 16.9 & 4.6 & 3.8 & $\mathbf{1 . 7 7}$ \\
Final exam & 63.8 & 20.0 & 10.0 & 2.3 & 1.5 & $\mathbf{1 . 5 4}$ \\
Term paper & 71.5 & 13.8 & 10.0 & 1.5 & 1.5 & $\mathbf{1 . 4 5}$ \\
Team project & 79.2 & 5.4 & 9.2 & 2.3 & 1.5 & $\mathbf{1 . 3 8}$ \\
\hline
\end{tabular}

* Average score was calculated using a point system with $1=$ Never and $5=10+$ times.

Table 3: Pressures that led respondents to consider cheating in a specific instance

\begin{tabular}{|l|c|c|c|}
\hline Response & Count & $\begin{array}{c}\text { \% of all } \\
\text { responses }\end{array}$ & $\begin{array}{c}\text { \% of valid } \\
\text { responses }\end{array}$ \\
\hline Not enough time & 36 & 20.7 & 23.1 \\
Unprepared & 22 & 12.6 & 14.1 \\
Lack of motivation & 17 & 9.8 & 10.9 \\
Grade pressure & 16 & 9.2 & 10.3 \\
Professor deserved it & 14 & 8.0 & 9.0 \\
Material too hard & 13 & 7.5 & 8.3 \\
Easy to cheat & 10 & 5.7 & 6.4 \\
Lazy or procrastinated & 7 & 4.0 & 4.5 \\
Cheating works & 7 & 4.0 & 4.5 \\
It's not cheating & 6 & 3.4 & 3.8 \\
Everyone does it & 2 & 1.1 & 1.3 \\
Others needed it (my help) & 1 & 0.6 & 0.6 \\
Could not be determined & 5 & 2.9 & 3.2 \\
Blank or unrelated response & 18 & 10.3 & - \\
\hline Total & 174 & 100.0 & 100.0 \\
\hline
\end{tabular}


Does Academic Dishonesty Relate to Unethical Behavior in Professional Practice?

Table 4: Factors that caused respondents to hesitate in cheating

\begin{tabular}{|l|c|c|c|}
\hline Response & Count & $\begin{array}{c}\text { \% of all } \\
\text { responses }\end{array}$ & $\begin{array}{c}\text { \% of valid } \\
\text { responses }\end{array}$ \\
\hline Shame, conscience, guilt or loss of & 22 & 14.8 & 17.7 \\
personal respect & 17 & 11.4 & 13.7 \\
Desire to learn & 16 & 10.7 & 12.9 \\
Desire to do own work & 13 & 8.7 & 10.5 \\
Fear or high probability of getting caught & 12 & 8.1 & 9.7 \\
Fear of sanctions & 11 & 7.4 & 8.9 \\
No hesitation & 11 & 7.4 & 8.9 \\
Cheating is wrong & 5 & 3.4 & 4.0 \\
Cheating is against the rules & 4 & 2.7 & 3.2 \\
Physically too hard or time consuming & 2 & 1.3 & 1.6 \\
It won't get you anything & 2 & 1.3 & 1.6 \\
Would lose respect of others & 9 & 6.0 & 7.3 \\
Could not be determined & 25 & 16.8 & - \\
Blank or unrelated response & 124 & 100.0 & 100.0 \\
\hline Total & & & \\
\hline
\end{tabular}

Table 5: Decision about cheating based on form of assessment

\begin{tabular}{|c|c|c|}
\hline \multirow{2}{*}{ Form of assessment } & \multicolumn{2}{|c|}{$\begin{array}{l}\text { Decision about cheating } \\
\text { (number of respondents in parentheses) }\end{array}$} \\
\hline & $\begin{array}{c}\text { Did cheat } \\
\text { (36.2\% of respondents) }\end{array}$ & $\begin{array}{c}\text { Did not cheat } \\
\text { (50.0\% of respondents) }\end{array}$ \\
\hline Lab report & $66.7 \%(6)$ & $33.3 \%(3)$ \\
\hline Computer program & $58.3 \%(7)$ & $41.7 \%(5)$ \\
\hline Homework & $45.2 \%(19)$ & $54.8 \%(23)$ \\
\hline Test or quiz & $33.3 \%(11)$ & $66.7 \%(22)$ \\
\hline Team project & $33.3 \%(1)$ & $66.7 \%(2)$ \\
\hline Final exam & $14.3 \%(1)$ & $85.7 \%(6)$ \\
\hline Term paper & $0 \%$ & $100 \%(1)$ \\
\hline Other & $0 \%$ & $100 \%(1)$ \\
\hline
\end{tabular}


T. S. Harding, D. D. Carpenter, C. J. Finelli, H. J. Passow

Table 6: Frequency with which respondents were tempted to violate workplace policies for various scenarios.

\begin{tabular}{|l|c|c|c|c|c|c|}
\hline Scenario & $\begin{array}{c}\text { Never } \\
(\%)\end{array}$ & $\begin{array}{c}\text { Once } \\
(\%)\end{array}$ & $\begin{array}{c}2-5 \\
\text { times } \\
(\%)\end{array}$ & $\begin{array}{c}5-10 \\
\text { times } \\
(\%)\end{array}$ & $\begin{array}{c}10+ \\
\text { times } \\
(\%)\end{array}$ & $\begin{array}{c}\text { Average } \\
\text { score* }\end{array}$ \\
\hline Use company supplies & 51.2 & 14.4 & 25.6 & 3.2 & 5.6 & 1.98 \\
improperly & 64.6 & 6.9 & 17.7 & 2.3 & 4.6 & 1.70 \\
Falsify records & 77.6 & 7.2 & 12.8 & 1.6 & 0.8 & 1.41 \\
Ignore quality problems & 79.2 & 5.4 & 6.2 & 3.8 & 1.5 & 1.37 \\
Lie about work quality & 84.8 & 8.0 & 5.6 & 1.6 & 0.0 & 1.24 \\
Ignore safety problems & 88.8 & 5.6 & 4.8 & 0.8 & 0.0 & 1.18 \\
Accept improper gifts & 90.4 & 4.8 & 4.0 & 0.8 & 0.0 & 1.15 \\
Take credit for another's work & &
\end{tabular}

* Average score was calculated using a point system with $1=$ Never and $5=10+$ times.

Table 7: Pressures that led respondents to consider violating workplace policies in a specific instance

\begin{tabular}{|l|c|c|c|}
\hline Response & Count & $\begin{array}{c}\text { \% of all } \\
\text { responses }\end{array}$ & $\begin{array}{c}\text { \% of valid } \\
\text { responses }\end{array}$ \\
\hline Wanted or needed it & 19 & 13.7 & 21.8 \\
Inconsequential or seemed harmless & 9 & 6.5 & 10.3 \\
The company deserved it & 7 & 5.0 & 8.0 \\
Lack of time, money, or equipment to do & 7 & 5.0 & 8.0 \\
job correctly & 5 & 3.6 & 5.7 \\
Wanted to seem better than I was & 4 & 2.9 & 4.6 \\
Others needed my help & 4 & 2.9 & 4.6 \\
Didn't want to put forth the effort & 4 & 2.9 & 4.6 \\
Everyone does it & 3 & 2.2 & 3.4 \\
It's easy or easy to get away with & 3 & 2.2 & 3.4 \\
Not confident in my abilities & 3 & 2.2 & 3.4 \\
Wanted to avoid conflict with others & 3 & 2.2 & 3.4 \\
Someone told me to do it & 2 & 1.4 & 2.3 \\
No one would care & 1 & 0.7 & 1.1 \\
No pressures or it isn't wrong & 1 & 0.7 & 1.1 \\
Didn't know it was wrong & 12 & 8.6 & 13.8 \\
Could not be determined & 52 & 37.4 & - \\
Blank or unrelated response & 139 & 100.0 & 100.0 \\
\hline Total & &
\end{tabular}


Does Academic Dishonesty Relate to Unethical Behavior in Professional Practice?

Table 8: Factors that caused respondents to hesitate in violating workplace policies

\begin{tabular}{|l|c|c|c|}
\hline Response & Count & $\begin{array}{c}\text { \%of all } \\
\text { responses }\end{array}$ & $\begin{array}{c}\text { \% of valid } \\
\text { responses }\end{array}$ \\
\hline No hesitation & 11 & 7.7 & 13.8 \\
Personal standards (pride or integrity) & 11 & 7.7 & 13.8 \\
Might be fired or get in trouble & 11 & 7.7 & 13.8 \\
Fear of getting caught & 8 & 5.6 & 10.0 \\
It is wrong & 8 & 5.6 & 10.0 \\
Would lose respect of others & 5 & 3.5 & 6.3 \\
Shame, conscience or guilt & 5 & 3.5 & 6.3 \\
There would be negative consequences & 4 & 2.8 & 5.0 \\
for customer & 3 & 2.1 & 3.8 \\
Work had to get done & 3 & 2.1 & 3.8 \\
Could affect product quality & 2 & 1.4 & 2.5 \\
Is or could be illegal & 2 & 1.4 & 2.5 \\
Could be more work/money later & 7 & 4.9 & 8.8 \\
Could not be determined & 62 & 43.7 & - \\
Blank or unrelated response & 142 & 100.0 & 100.0 \\
\hline Total & & & \\
\hline
\end{tabular}

Table 9: Decision about violating workplace policies based on type of scenario

\begin{tabular}{|l|c|c|c|}
\hline \multirow{2}{*}{ Type of scenario } & \multicolumn{3}{|c|}{$\begin{array}{c}\text { Decision about violating workplace policies } \\
\text { (number of respondents in parentheses) }\end{array}$} \\
\cline { 2 - 4 } & $\begin{array}{c}\text { Did } \\
(30.0 \% \text { of } \\
\text { respondents) }\end{array}$ & $\begin{array}{c}\text { Did } \text { not } \\
(15.4 \% \text { of } \\
\text { respondents) }\end{array}$ & $\begin{array}{c}\text { Other } \\
(10.8 \% \text { of } \\
\text { respondents) }\end{array}$ \\
\hline Improperly use company supplies & $73.1 \%(19)$ & $19.2 \%(5)$ & $7.7 \%(2)$ \\
Falsify records & $53.8 \%(14)$ & $19.2 \%(5)$ & $26.9 \%(7)$ \\
Accept improper gifts & $50.0 \%(1)$ & $50.0 \%(1)$ & $0.0 \%$ \\
Ignore quality problems & $42.9 \%(3)$ & $57.1 \%(4)$ & $0.0 \%$ \\
Take credit for other's work & $33.3 \%(1)$ & $33.3 \%(1)$ & $33.3 \%(1)$ \\
Lie about work quality & $25.0 \%(1)$ & $50.0 \%(2)$ & $25.0 \%(1)$ \\
Don't report safety problems & $0.0 \%$ & $50.0 \%(1)$ & $50.0 \%(1)$ \\
\hline
\end{tabular}

Table 10: Decision about cheating in college and about violating workplace policies based on self-reported frequency of cheating in high school

\begin{tabular}{|l|c|c|c|c|c|}
\hline \multirow{2}{*}{$\begin{array}{l}\text { Frequency of } \\
\text { cheating in high school }\end{array}$} & \multicolumn{3}{|c|}{$\begin{array}{c}\text { Decision about } \\
\text { cheating in college }\end{array}$} & \multicolumn{3}{|c|}{$\begin{array}{c}\text { Decision about } \\
\text { violating workplace policies }\end{array}$} \\
\cline { 2 - 6 } & Did & Did not & Did & Did not & Other \\
\hline Never & $31.6 \%$ & $68.4 \%$ & $37.5 \%$ & $50.0 \%$ & $12.5 \%$ \\
Once & $47.1 \%$ & $52.9 \%$ & $44.4 \%$ & $44.4 \%$ & $11.1 \%$ \\
A few times & $40.3 \%$ & $59.7 \%$ & $56.8 \%$ & $25.0 \%$ & $18.2 \%$ \\
Frequently & $61.5 \%$ & $38.5 \%$ & $63.6 \%$ & $9.1 \%$ & $27.3 \%$ \\
\hline
\end{tabular}


T. S. Harding, D. D. Carpenter, C. J. Finelli, H. J. Passow

Table 11: Common responses about pressures to cheat and to violate workplace policies

\begin{tabular}{|c|c|c|}
\hline $\begin{array}{c}\text { Name for common } \\
\text { response }\end{array}$ & Pressure to cheat & $\begin{array}{l}\text { Pressure to violate } \\
\text { workplace policies }\end{array}$ \\
\hline Insufficient resources & Not enough time & $\begin{array}{l}\text { Lack of time, money, or } \\
\text { equipment to do job }\end{array}$ \\
\hline Importance of success & Grade pressure & $\begin{array}{c}\text { Wanted to seem better than } \\
\text { I was }\end{array}$ \\
\hline Projection of blame & Professor deserved it & The company deserved it \\
\hline Chance of success & Material too hard & $\begin{array}{c}\text { Not confident in my } \\
\text { abilities }\end{array}$ \\
\hline Risk of detection & Easy to cheat & $\begin{array}{l}\text { It's easy or easy to get away } \\
\text { with }\end{array}$ \\
\hline Industriousness & Lazy or procrastinated & $\begin{array}{l}\text { Didn't want to put forth the } \\
\text { effort }\end{array}$ \\
\hline Attitude & It's not cheating & $\begin{array}{l}\text { It isn’t wrong, I didn’t } \\
\text { know it was wrong }\end{array}$ \\
\hline Perceived norms & Everyone does it & Everyone does it \\
\hline Peer influence & Others needed my help & Others needed my help \\
\hline
\end{tabular}

Table 12: Common responses about hesitations to cheat and to violate workplace policies

\begin{tabular}{|c|c|c|}
\hline $\begin{array}{c}\text { Name for common } \\
\text { response }\end{array}$ & Hesitation to cheat & $\begin{array}{l}\text { Hesitation to violate } \\
\text { workplace policies }\end{array}$ \\
\hline Conscience & $\begin{array}{l}\text { Shame, conscience, guilt or } \\
\text { lack of personal respect }\end{array}$ & Shame, conscience or guilt \\
\hline Moral obligation & $\begin{array}{l}\text { Desire to learn, desire to do } \\
\text { own work }\end{array}$ & $\begin{array}{l}\text { Personal standards } \\
\text { (pride/integrity) }\end{array}$ \\
\hline Risk of detection & $\begin{array}{c}\text { Fear or a high probability of } \\
\text { getting caught }\end{array}$ & Fear of getting caught \\
\hline Attitude & Cheating is wrong & It is wrong \\
\hline Risk of formal sanctions & Cheating is against the rules & Is or could be illegal \\
\hline Expected value of success & It won't get you anything & $\begin{array}{l}\text { Could be more work/money } \\
\text { later }\end{array}$ \\
\hline Influence of others & $\begin{array}{l}\text { Would lose respect of } \\
\text { others }\end{array}$ & $\begin{array}{c}\text { Would lose respect of } \\
\text { others }\end{array}$ \\
\hline
\end{tabular}

